\title{
Innovation Theoretical Research and Countermeasure Analysis of Physical Education in Colleges and Universities
}

\author{
Ye Min \\ Guangdong University of Petrochemical Technology, 525000, Maoming China
}

Keywords: Sports teaching; development of theory; Quality education

\begin{abstract}
Improve student physique, raise the level of students' health is the foundation of sports teaching. Reasonable teaching method not only can make the teaching effect of get twice the result with half the effort, would also benefit the students for life. In recent years, with the deepening of the curriculum reform, the old teaching model is gradually being broken, teaching idea, content, methods, in the event of a change. Through the analysis of the existing sports teaching pattern in colleges and universities, to find out the problems existing in the teaching, around the teaching concept of "health first, sports for life", puts forward feasible Suggestions on university sports teaching theory innovation, the purpose is fundamentally changing the existing teaching mode, realize the students' physical and mental health, for the reform and development of sports teaching in colleges and universities to provide certain reference.
\end{abstract}

\section{Introduction}

The teaching method reform is the extension and expansion of quality education and deepening, is an important approach to train high quality creative talent. Through innovation of colleges and universities sports teaching theory research, to update teaching ideas, improve the teaching quality and efficiency; Also can improve students' ability of independent thinking, develop good exercise habits.

The national medium and long-term education reform and development plan outline (2010-2020) "proposed that the reform and innovation as the development of education. Reform the teaching contents, methods, means, cultivate students' innovative ability[1]. In order to meet the quality of education the general requirements, this paper revolves around the innovation education idea, study on physical education teaching methods. Adopt the method of questionnaire to summarize the current problems existing in the sports teaching, and in view of the problem, this paper proposes the methods of physical education teaching innovation and Suggestions: put forward the "health first, lifelong sports" as the guiding ideology, takes student's main body status, arouses student's enthusiasm and creativity; Reform focuses on traditional non-computer majors, the teaching method of teaching, explore the teaching methods such as heuristic, exploratory, remote integration teaching mode, to enhance students' physique, improve the level of student health and provides some references for the teaching quality.

\section{Current problems that exist in sports teaching activities}

Differences in course content and student needs. The survey found that a lot of college sports in the curriculum remained in the traditional athletics, ball games, martial arts and other projects, the students are more interested in sports, such as badminton, swimming, table tennis and other projects open less, resulting in physical education curriculum content and student needs a certain gap exists, the lack of students in class when positive initiative[2]. The main reason causing this problem except by teaching environment, teachers influence, but also affected the cost of inputs, some schools in order to reduce capital investment, reluctant to increase student favorite sport.

Too much emphasis on results, evaluation methods unreasonable. Physical Education Teaching evaluation is an important part of sports, and provide feedback to teachers teaching, help to adjust the teaching content, improve teaching methods. Currently, sports teaching evaluation method is relatively simple, relatively narrow scope of the evaluation, the evaluation is limited to 
target students. This evaluation is a meta-evaluation is limited to physical education teachers on student evaluation, lack of teachers and curriculum evaluation, the degree of movement of students to master the technology and the evaluation of the physical condition of the proportion is too large to ignore the attitude of the students, psychological and Evaluation of behavior. Meanwhile, the lack of subject participation in sports teaching evaluation mechanism, that is, the existing evaluation system, students cannot be self-evaluation, learning is good or bad can only be evaluated by teachers, lack of objectivity in this way, is not conducive to quality education, but do not meet the "health first" guiding ideology.

Teaching methods single. The teaching method of teaching has a close relationship with the effect. At present, many colleges and universities sports teaching is still mainly with the method of explanation and demonstration. But with the continuous deepening of the reform of teaching, cultivate students' interest in sports, form a good habit, improve sports ability is the ultimate goal of physical education curriculum teaching. Therefore, teachers should pay more attention to development in the sports teaching the students' personality, respect students' choice, take more ways, to mobilize students' learning interest and initiative.

To further illustrate the problems existing in the sports teaching at present, the questionnaire survey was conducted among 1000 students, the results of the survey is shown in figure 1.

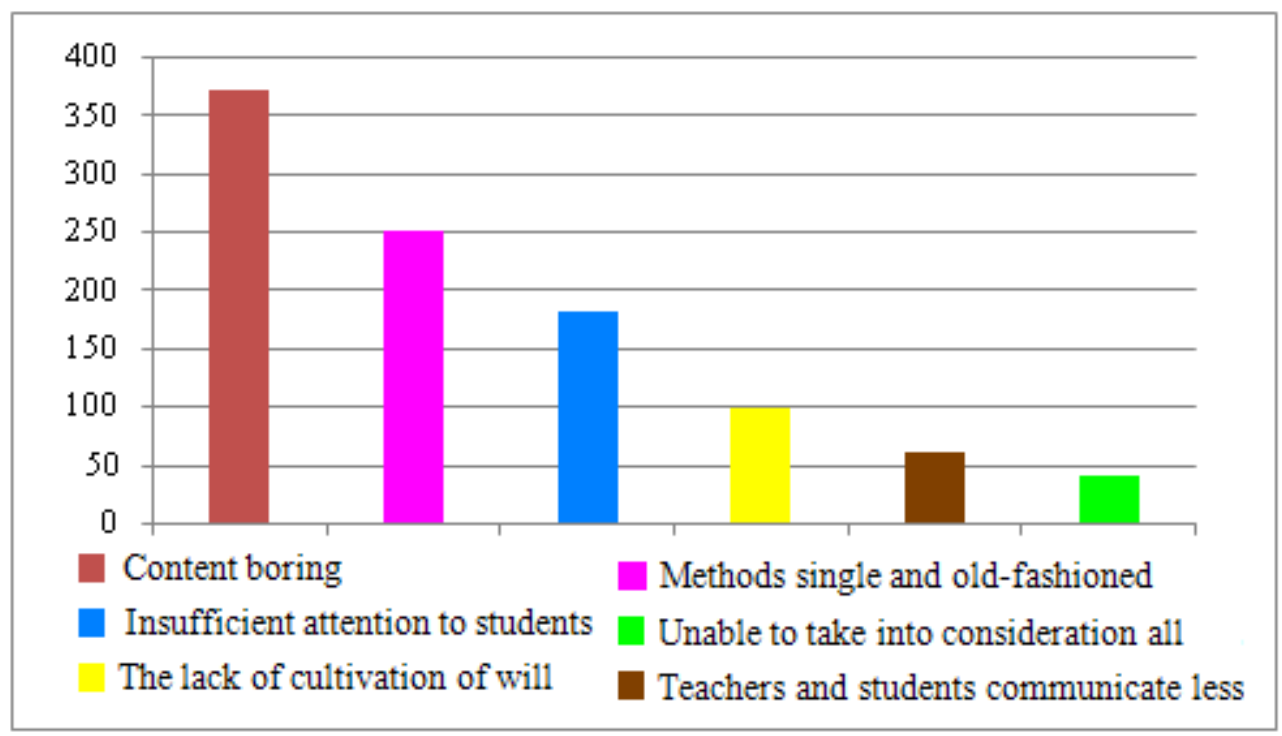

Fig.1 Students of the questionnaire for the opinions of the current education method

In 1000 the students of sports teaching method opinion questionnaire, "Content boring, not to stimulate students' interest and enthusiasm for exercise" in first place, a total of 370, accounting for $37 \%$ of the overall proportion of "old-fashioned teaching single, not enough attention to the students' problems also accounted for a large proportion.

\section{Methods analysis of sports teaching}

Teaching method relates to the success or failure of teaching activities, teaching efficiency. The essence of teaching activities is that teachers imparting knowledge and skills to students and students' own digestion process. In this process, the teaching methods play a key role, it is not only related to the effects of teaching, relationship to the process and efficiency of students internalize knowledge skills, also with the students' ability to find and solve problems.

According to the main body in the process of sports teaching and the focus of the teaching methods, the teaching method is divided into two categories[3]. The first is "give priority to in order to teach" sports teaching methods, such as the demonstration method. Outstanding PE teachers teaching function, the "teaching" as the main access to knowledge and skills, in view of the "teaching" as the core of the teaching methods. The second category is "give priority to in order to learn" sports teaching methods, such as discovery method. Highlighting how to make students 
better acquire knowledge, in view of the "learning" as the core, according to the needs of the students design teaching methods. Look from the teaching content, the concept of the latter is more advanced, but an effective way of teaching activities should not be limited to, need to actively coordinate between teachers and students, interactive teaching, the relationship between handled well, can produce good teaching effect, relationship between teachers and teaching activities and the teaching effect is shown in figure 2.

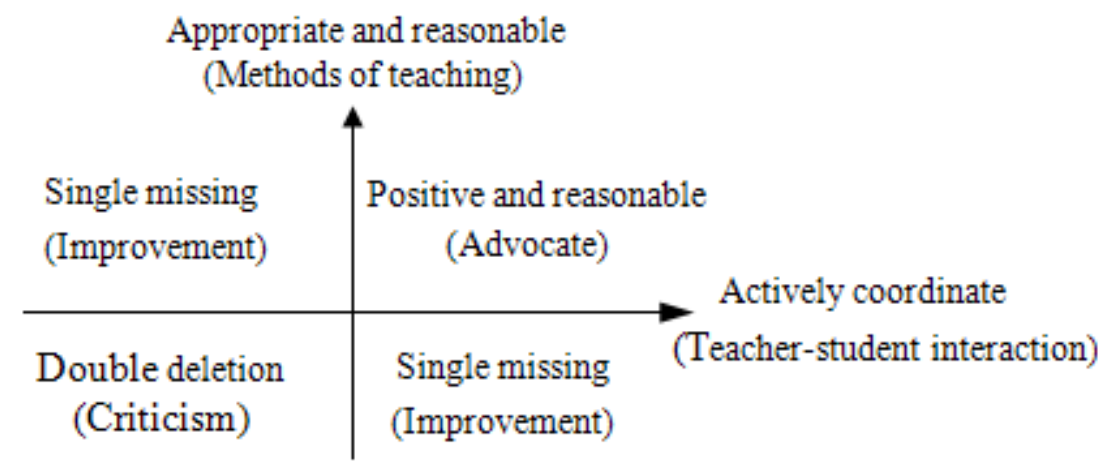

Fig.2 Relationship between teachers and teaching activities and teaching effect

\section{The design of the university sports teaching innovation model}

Sports teaching theory innovation, should establish the correct health concept, with "lifetime sports" as the guiding ideology, development conforms to the characteristic of sports teaching mode. Around improve college students' physical fitness, develop good sports habits, to establish a new and scientific course system, practical for the contemporary college students sports needs to find a feasible way.

Connotation of innovation education. Innovation education is an important part of quality education, the basic goal is to cultivate students' innovation spirit and innovation ability, the purpose is to explore the creative potential of people, carry forward the main body of the human spirit, and promote the comprehensive development. Education innovation including the content of the education goal, content, the reform of adjustment, the method of many problems, is the important way of cultivating high-quality talents. Education innovation to cultivate innovative talents, shaping the personality as a starting point, is the rational knowledge of education basic law and judgment[4], the difference between innovation education and traditional education as shown in table 1.

Tab.1 Difference between the traditional education and innovation education

\begin{tabular}{ccc}
\hline & Traditional education & Innovative education \\
\hline Training Methods & Imitation and inheritance & Reform and development \\
\hline Process of learning & Storage and accumulation & Extraction and processing \\
\hline Learning attitude & Passive & Initiative \\
Form of teaching & Indoctrination & Heuristic \\
\hline
\end{tabular}

\section{Principles of Physical Education Theory Innovation.}

1) Principle of health

Traditional health refers to the body without the disease, and modern health is to point to in addition to the body without the disease, but also have good mental health, social adaptation and so on. Sports teaching is to enhance students' physique, improve the level of health as the main target. Health principles of physical education teaching, it is to point to in the sports teaching, adheres to 
the guiding ideology of "health first", promote students' physical and mental health development. At the same time, to create a healthy, can make the students happy PE teaching environment, to play a positive role in promoting students' physical and mental health.

2) Principle of optimization

Sports teaching optimization principle focus on the sports teaching system, is the optimized combination various teaching factors, in order to gain the best benefit principle. Sports teaching is in a certain teaching environment, teachers and students rely on the tutorial, using certain teaching methods and means, complete the teaching mission together. To make sports teaching achieve the best effect of learning, improve the quality of teaching, the teaching environment, teachers, teaching content, teaching mode, organizational form, the results of evaluation elements such as view, should be based on the principle of optimization.

3) Principle of developmental

Correctly grasp the developmental principle refers to the teacher the student ability level, focused on the development of students' potential and quality of the principle of comprehensive development. Physical education is not limited to, the general goal of teaching is a continuous process, to understand the true connotation of development, to meet the needs of the students' lifetime sports as the basic, pay attention to select students life-long sports have important influence on the basic knowledge, basic skills and activities. While completes the teaching content, let the students to explore new knowledge and skills, the ability of making sports continued to improve and deepen.

\section{Content of the theory of sports teaching innovation design.}

1) Develop "lifetime sports" concept, to establish "health first" guiding ideology

Cultivate moral, intellectual, physical all-round development of high-quality talent is the overall goal of the teaching in our country, physical education is always around the total target. The concept of sports teaching to cultivate talent correctly or not, is directly related to success or failure of the reform of school sports teaching, physical education guiding ideology is also directly affects the realization of teaching goals. According to the guidance of the outline, raises the concept of "lifetime sports", establish the guiding ideology of "health first", will be gradually dominated in the universities sports teaching.

Sports teaching is different from competitive sports training, cannot excessive pursuit of systemic and integrity, also cannot too much pursuit of exercise intensity, but should be suitable for the students' physical and mental development, lets the student in a harmonious atmosphere exercise, sports skill. Therefore, both in the choice of teaching contents, and teaching method reform, should strive to promote students' physical and mental health level and the improvement of social adaptation ability.

2) Change from teaching to guiding type teaching way

At present sports teaching mainly take "learning type" teaching method, namely as teachers action demonstration as the forerunner, causes the student to obtain technical movement of perceptual knowledge, to master the skill of laying a foundation for rational knowledge. The teaching method content boring, single, cannot arouse students interest and enthusiasm.

Aiming at this problem, the teaching method should be to teach type teaching method to organize and guide. College students of sports learning often does not need too many sermons, also do not need meticulous decomposition practice, but is attracted to their learning of exercise teaching environment more appropriate to them. This kind of teaching method called "guide learning" teaching, namely to guide after the "learn" as the basic characteristics, its main function is through self-study, make students understand and master the knowledge and skills, the teacher in the student after the practice of explanation and demonstration are key around the challenges from the students or teaching emphasis earnestly and inspiration. Through this way of teaching, make students get knowledge to explore fresh feeling of success and self.

The application of multimedia network teaching in physical education teaching.

Compared with traditional sports teaching, multimedia network teaching has the following advantages[5]: 
1) Increase the teaching effect, make the teaching content more intuitive

Traditional sports teaching, the teacher for technical movements and main point of teaching mainly through the explanation and demonstration to complete, but in the interest of time, many techniques cannot unlimited repeated demonstration, which made some comprehension ability of students with poor technical movement irregular or not correct in a timely manner. Multimedia network teaching can well solve the problem, through suspension, slowed down and playback, can better rendering techniques to learn, so that the students will soon be able to understand and grasp.

2) Overcome the regional differences of sports teaching

Due to China's economic development is uneven, resulting in differences in the level of each region Physical Education, teaching multimedia network applications can greatly improve this problem. Through multimedia network teaching platform, the resources can be shared among universities, complementary advantages. Students on the basis of self-learning, and teachers can also be remote "face to face" communication, for online interaction to improve the teaching level and efficiency.

3) Multimedia network teaching to provide students with a personalized learning space

Traditional Physical Education teaching body is usually around teachers, teaching materials, physical education teachers is difficult to carry out targeted individualized instruction, resulting in student autonomy and personalized learning is difficult to achieve. Through multimedia network teaching, students can be independent and personalized learning based on the choice of teaching resources, cultivate the students' creativity and innovative thinking.

\section{Conclusion}

Education as an educational philosophy, emphasizing the ability of students, and teaching methods will play an important role in quality education. By analyzing the College Physical Education in the existing problems, this article focuses on a "science-based" and "teachingoriented" relations between the two sports teaching methods, and health, and optimality, the development of the principle of proposed countermeasures against the teaching of the problem. Research results indicate that physical education should be effective to break the traditional teaching model, teachers not only to impart knowledge, but more importantly is to guide students to master learning methods to form good study habits, to stimulate their interest in sports. Improve the quality of teaching at the same time, adhere to the "Health First, Lifelong Physical" teaching philosophy, students lifetime.

\section{References}

[1] Howard Gardner. Intelligence Reframed: Multiple Intelligences for the 21th Century[M].The Palmer, 2000.

[2] Vida Skudiene. Quality of Undergraduate Management of Studies in a Changing University Environment[J].Quality of Higher Education,2005, 12:166-173.

[3] H. Wang, F. Shkjezi, and E. Hoxha. Distance metric learning for multi-camera people matching, in Advanced Computational Intelligence (ICACI), 2013 Sixth International Conference on. IEEE, 2013:140-143.

[4] Neil Hamilton. Faculty Professionalism: Failures of Socialization and the Road[J]. Liberal Education, 2006,40:14-21.

[5] Bruce Macfarlane. Gwyneth Hughes. Turning teachers into academics? The role of educational development in fostering synergy between teaching and research [J]. Innovations in Education and Teaching International, 2009,46(1):5-14. 